\title{
Analysis of the behaviour of fusing systems in the presence of non linear loads
}

\author{
J. DESMET, G. VANALME, K. STOCKMAN \\ Hogeschool West-Vlaanderen, dept. P.I.H. \\ Graaf Karel de Goedelaan 5 \\ B-8500 Kortrijk \\ Belgium \\ E-mail: desmetji.pih@hogeschool-wvl.be
}

\author{
R. BELMANS \\ K.U.Leuven, dept. ESAT/ELEN \\ Kasteelpark Arenberg 10 \\ B-3001 Leuven \\ Belgium \\ E-mail: ronnie.belmans@esat.kuleuven.ac.be
}

\begin{abstract}
This paper describes the behaviour of fusing systems in the presence of both non-linear single phase and three phase loads. Such loads, producing harmonic currents, yield high peak currents [1,2]. Specifically, ITequipment where the non-linearity is caused by the bridge rectifier of the switching power supply [3] and variable speed drives are considered [2]. The paper presents the study of the influence of the waveform of the neutral conductor current on the behaviour of the fusing system.

Using a programmable power source, an arbitrary voltage waveform is generated. Each phase is loaded by a variable number of resistors. For different set ups of the power source and load conditions, the phase currents are analysed using on-line monitoring. The ratio of the phase rms to peak current on the behaviour of fusing systems is analysed.
\end{abstract}

KEY WORDS: power quality parameters, ITequipment, non-linear loads, fusing

\section{INTRODUCTION}

Nowadays both variable speed drives and ITequipment, such as monitors, PC's, printers, faxes are widely spread. These apparatus have a non-linear terminal supply behaviour: they produce harmonic currents e.g. due to the high peak currents $[4,5,6]$. However, in practice, fusing of most installations is not rated accounting for non sinusoidal currents.

In this paper comprehensive measurements are discussed on fusing systems in order to predict the behaviour in case of high peak currents. For different set ups, both inrush and steady state current behaviour are analysed. All currents are also measured and compared to the operating ranges of the normative reference [7]. Finally, the fusing of the neutral conductor is studied for different load conditions.

\section{ANALYSIS OF THE CURRENT OF NON LINEAR LOADS}

\subsection{Measurements on non linear sine phase loads}

In order to determine the current waveform of IT equipment, 19 monitors and 9 PC's are tested. All monitors and PC's show similar current fingerprints (fig.1). This can be explained by the similar topology of the switching power supply of the devices.

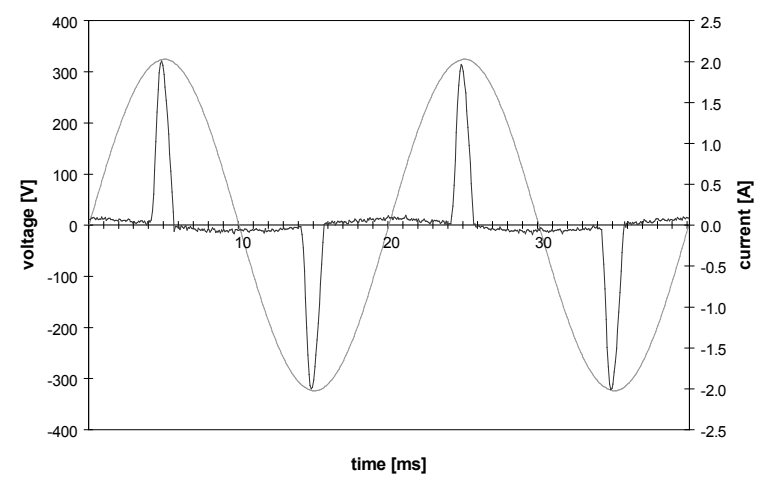

Fig. 1 Current and corresponding voltage of a monitor. The current fingerprint is typical for all tested monitors and PC's.

\subsection{Measurements on non linear three phase loads}

The current waveforms of 21 variable speed induction motor drive systems, having different types of six-pulse full bridge converters with respect to the electric quantities, including power quality parameters, are analysed [2]. All drives show two different groups of similar current fingerprints (fig.2 and fig.3). This can be explained by the different topology of the power supply of the drive systems, i.e. the presence or absence of a current variation limiting coil.

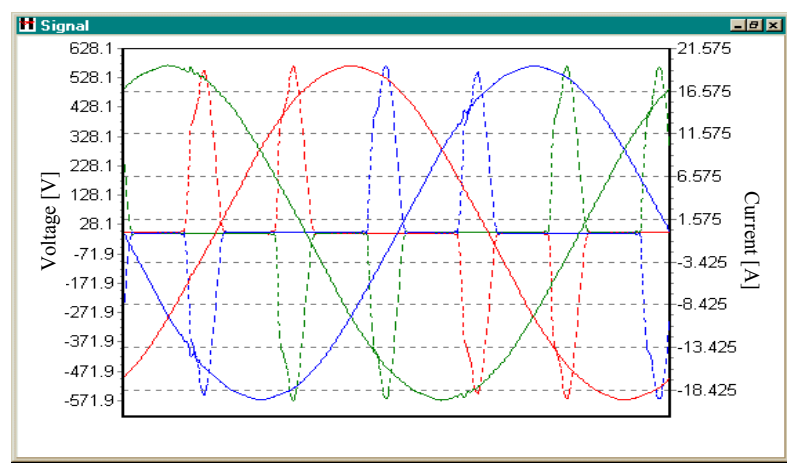

Fig. 2 Currents and corresponding voltages of a drive. The current fingerprint is typical for all tested drives without coil in the rectifier circuit. 


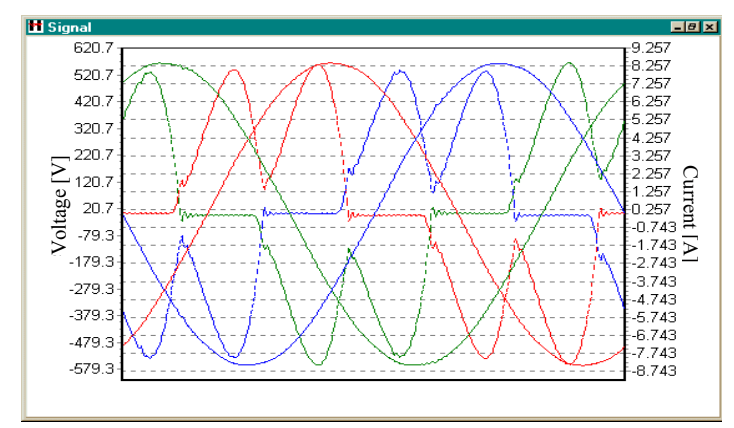

Fig. 3 Currents and corresponding voltages of a drive. The current fingerprint is typical for all tested drives with coil in the rectifier circuit.

\subsection{Analysis of the neutral conductor current}

The presence of non linear single phase loads in a 4 wire supply system may yield high values of the neutral conductor current [4]. Fig. 4 shows the rms-values of neutral conductor and phase currents versus the number of PC's in each phase when a symmetric and balanced three phase supplied network with load consisting of the same PC's are considered [6].

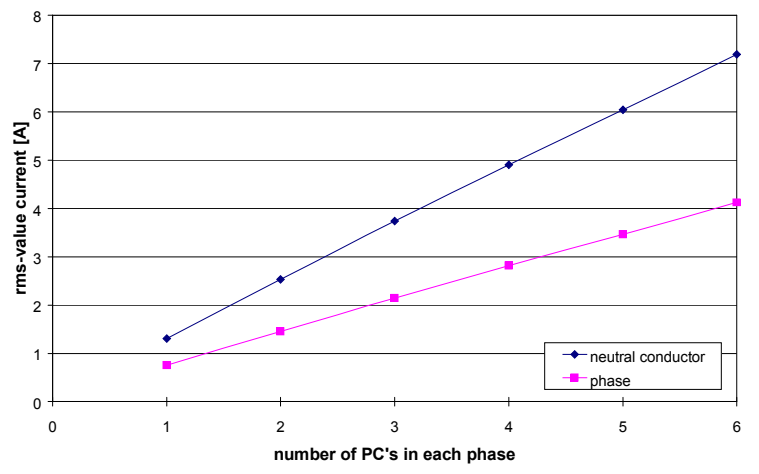

Fig. 4 Dependence of the rms-values of neutral and phase currents on the load in case of a symmetric and balanced network.

The neutral conductor current can attain a value up to 1.73 times the phase current due to the high harmonic currents produced by the non linear loads [8].

\section{TEST CONFIGURATION}

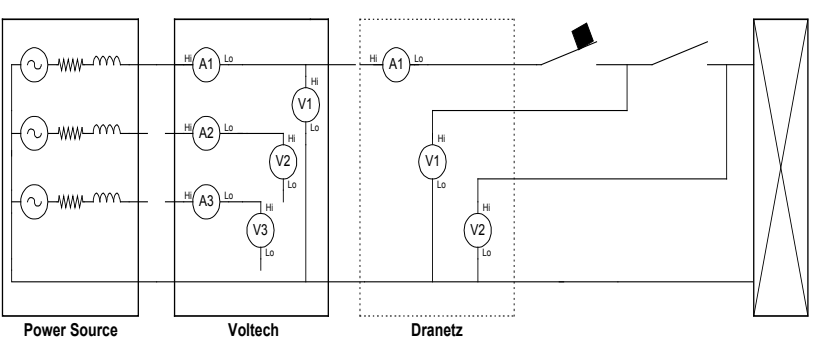

Fig. 5. Measurement set-up
Using a programmable power source, a voltage with the same waveform as the current waveform of a non linear load, is generated on a single phase. The phase is loaded with a resistive load. In this way, the waveform of the current through the fuse is the same as the waveform of the non linear load and moreover, the rms-value of the fuse current can be chosen. Measurements of phase currents are done using a high performance power analyser.

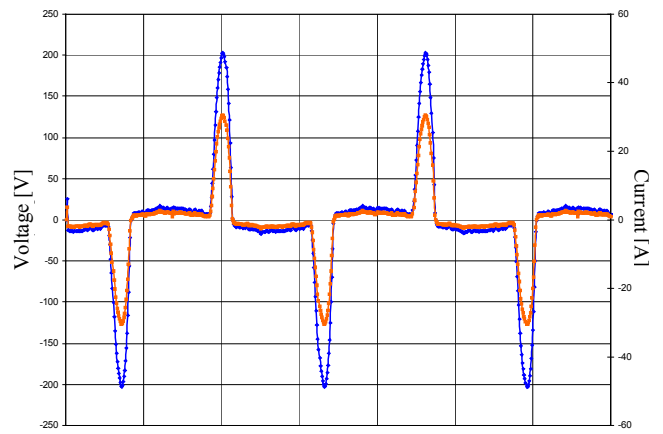

Fig. 6 Voltage waveform generated by the power source and measured current.

Both conditions, steady state (Fig. 6) and inrush mode (Fig. 7) are considered. The same set ups are used to analyse the behaviour of fusing systems for both neutral conductor current and drives.

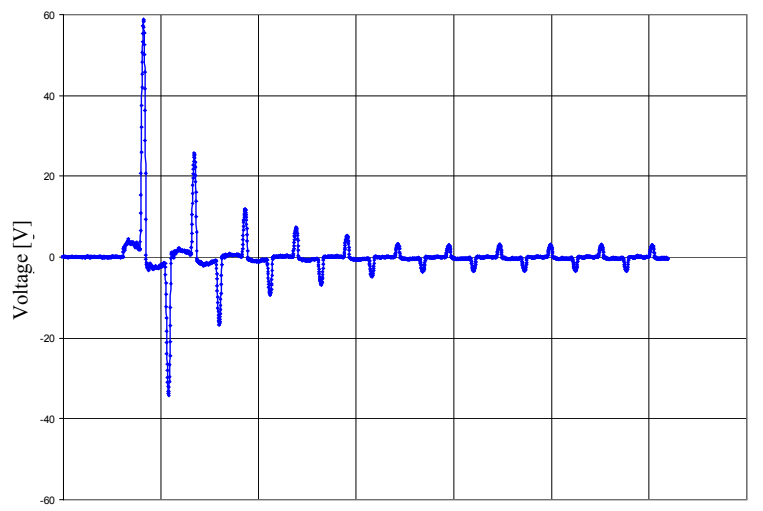

Fig. 7 Voltage waveform generated by the power source used for inrush analysis.

\section{TEST RESULTS}

\subsection{Analysis of normative reference}

The normative reference [7] defines the requirements for automatic fuses installed in residential installations. The thermal ranges for automatic fuses are given in table I, while the magnetic ranges are given in table II. The symbols $t_{u}$ and $I_{n}$ represent the switch off time and the nominal rated current of the fuse respectively. 
Thermal range:

Table I: Thermal ranges for automatic fuses

\begin{tabular}{|l|l|}
\hline Test current & Switch off time \\
\hline \hline $1,13 \mathrm{I}_{\mathrm{n}}$ & $\begin{array}{l}\mathrm{t}_{\mathrm{u}} \geq 1 \mathrm{~h}\left(\mathrm{I}_{\mathrm{n}} \leq 63 \mathrm{~A}\right) \\
\mathrm{t}_{\mathrm{u}} \geq 2 \mathrm{~h}\left(\mathrm{I}_{\mathrm{n}}>63 \mathrm{~A}\right)\end{array}$ \\
\hline $1,45 \mathrm{I}_{\mathrm{n}}$ & $\begin{array}{l}\mathrm{t}_{\mathrm{u}}<1 \mathrm{~h}\left(\mathrm{I}_{\mathrm{n}} \leq 63 \mathrm{~A}\right) \\
\mathrm{t}_{\mathrm{u}}<2 \mathrm{~h}\left(\mathrm{I}_{\mathrm{n}}>63 \mathrm{~A}\right)\end{array}$ \\
\hline $2,55 \mathrm{I}_{\mathrm{n}}$ & $\begin{array}{l}1 \mathrm{~s}<\mathrm{t}_{\mathrm{u}}<60 \mathrm{~s} \text { for } \mathrm{I}_{\mathrm{n}} \leq 32 \mathrm{~A} \\
1 \mathrm{~s}<\mathrm{t}_{\mathrm{u}} \leq 120 \text { s for } \mathrm{I}_{\mathrm{n}}>32 \mathrm{~A}\end{array}$ \\
\hline
\end{tabular}

In the magnetic range, three ranges are considered:

Table II: Magnetic ranges for automatic fuses

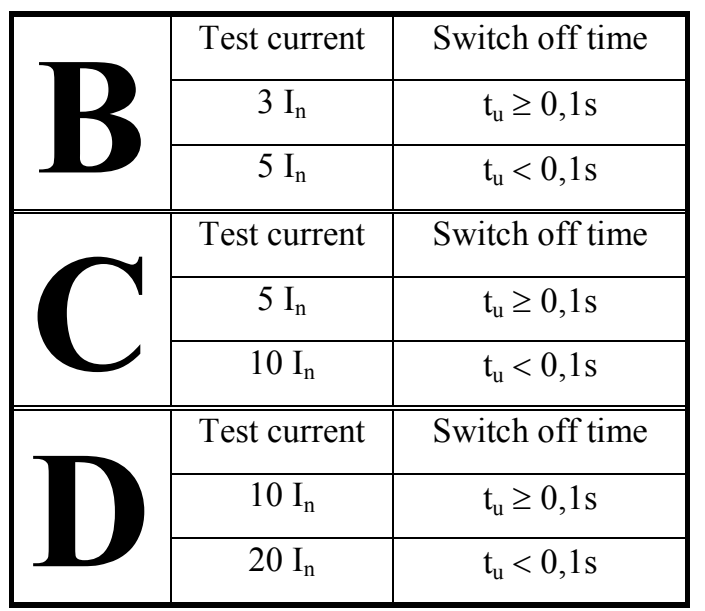

\subsection{Results of analysis}

Tables III and IV compare the thermal reaction of an automatic fuse (steady state condition) to the normative reference in case of sinusoidal and non linear currents respectively. Notice that the rms-values of the sinusoidal and non linear currents are approximately the same.

Table III : Sine wave current, thermal behaviour for FAZ-1N-B6

\begin{tabular}{|r|c|r|c|}
\hline $\begin{array}{c}\mathrm{I}_{\mathrm{RMS}} \\
{[\mathrm{A}]}\end{array}$ & $\mathrm{I}_{\mathrm{RMS}} / \mathrm{I}_{\mathrm{n}}$ & $\begin{array}{c}\text { Switch off } \\
\text { time }\end{array}$ & $\begin{array}{c}\text { normative ref. } \\
\text { fulfilled }\end{array}$ \\
\hline \hline 6,929 & $\cong 1,13$ & $>1 \mathrm{~h} 30$ & Yes \\
\hline 8,792 & $\cong 1,45$ & $20^{\prime} 40^{\prime}$ & Yes \\
\hline 13,804 & 2.30 & $10^{\prime}$ & Yes \\
\hline
\end{tabular}

Table IV : Non linear current, thermal behaviour for FAZ-1N-B6

\begin{tabular}{|r|c|r|c|}
\hline $\begin{array}{c}\mathrm{I}_{\mathrm{RMS}} \\
{[\mathrm{A}]}\end{array}$ & $\mathrm{I}_{\mathrm{RMS}} / \mathrm{I}_{\mathrm{n}}$ & $\begin{array}{c}\text { Switch off } \\
\text { time }\end{array}$ & $\begin{array}{c}\text { normative ref. } \\
\text { fulfilled }\end{array}$ \\
\hline \hline 6,893 & $\cong 1,13$ & $>1 \mathrm{~h} 30$ & Yes \\
\hline 8,706 & $\cong 1,45$ & $1^{\prime} 50^{\prime}$ & Yes \\
\hline 13,628 & 2.27 & $5{ }^{\prime}$ & Yes \\
\hline
\end{tabular}

The results of the magnetic or transient behaviour of the fuse are given in tables V and VI. In both cases, sinusoidal and non linear current, the rms-value of the current was increased gradually to find the rms-value of the current at which the fuse switches magnetically.
Table V : Sine wave current, magnetic behaviour for FAZ-1N-B6

\begin{tabular}{|c|c|c|c|c|c|}
\hline $\begin{array}{c}\mathrm{I}_{\text {RMS }} \\
{[\mathrm{A}]}\end{array}$ & $\begin{array}{c}\mathrm{I}_{\text {Peak }} \\
{[\mathrm{A}]}\end{array}$ & $\begin{array}{c}\mathrm{I}_{\mathrm{Av}} \\
{[\mathrm{A}]}\end{array}$ & $\mathrm{I}_{\mathrm{RMS}} / \mathrm{I}_{\mathrm{n}}$ & $\begin{array}{c}\text { Magnetic } \\
\text { Switching }\end{array}$ & $\begin{array}{c}\text { normative } \\
\text { ref. fulfilled }\end{array}$ \\
\hline \hline 19.4 & 27.5 & 17.5 & 3.2 & No & Yes \\
\hline 20.5 & 29.0 & 18.5 & 3.4 & No & Yes \\
\hline 22.1 & 31.3 & 19.9 & 3.7 & No & Yes \\
\hline 23.3 & 33.0 & 21.0 & 3.9 & No & Yes \\
\hline 23.8 & 33.7 & 21.5 & 4.0 & Yes & Yes \\
\hline
\end{tabular}

Table VI : Non linear current, magnetic behaviour for FAZ-1N-B6

\begin{tabular}{|r|r|r|c|c|c|}
\hline $\begin{array}{c}\mathrm{I}_{\mathrm{RMS}} \\
{[\mathrm{A}]}\end{array}$ & $\begin{array}{c}\mathrm{I}_{\text {Peak }} \\
{[\mathrm{A}]}\end{array}$ & $\begin{array}{c}\mathrm{I}_{\mathrm{Av}} \\
{[\mathrm{A}]}\end{array}$ & $\mathrm{I}_{\mathrm{RMS}} / \mathrm{I}_{\mathrm{n}}$ & $\begin{array}{c}\text { Magnetic } \\
\text { Switching }\end{array}$ & $\begin{array}{c}\text { normative } \\
\text { ref. fulfilled }\end{array}$ \\
\hline \hline 4.9 & 14.8 & 2.6 & 0.8 & No & Yes \\
\hline 7.7 & 23.0 & 4.1 & 1.3 & No & Yes \\
\hline 10.6 & 31.9 & 5.7 & 1.8 & No & Yes \\
\hline 13.6 & 40.9 & 7.2 & 2.3 & No & Yes \\
\hline 17.1 & 51.5 & 9.1 & 2.9 & Yes & No \\
\hline
\end{tabular}

In table V and VI the same test conditions are used. The only difference was a slight deviation in test voltage. However, other test voltages show the same reactions. Peak and average values of the current are given too.

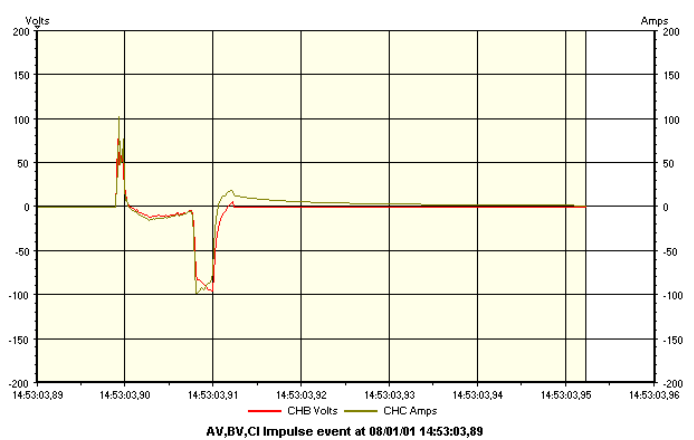

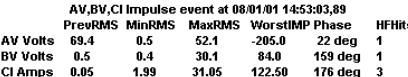

Fig. 8 Voltage and current waveform during magnetic tests.

Table VII : Sine wave current sweep until reaction for FAZ-1N-B6

\begin{tabular}{|l|r|r|r|r|r|r|r|r|r|r|r|r|}
\hline $\begin{array}{c}\text { Test } \\
\text { Voltage }\end{array}$ & \multicolumn{10}{|c|}{ SINE wave current: RMS-values until reaction [A] } \\
\hline $70 \mathrm{~V}$ & 16,4 & 17,1 & 17,6 & 18,3 & 18,9 & 19,5 & 20,2 & 20,5 & 21,2 & 23,1 & 23,8 & $\mathrm{R}$ \\
\hline $80 \mathrm{~V}$ & 18,8 & 19,8 & 20,3 & 20,8 & 21,7 & 22,4 & 23,3 & 23,7 & $\mathrm{R}$ & & & \\
\hline $90 \mathrm{~V}$ & 21,4 & 22,1 & 23,3 & 23,8 & $\mathrm{R}$ & & & & & & & \\
\hline $100 \mathrm{~V}$ & 24,4 & 24,9 & $\mathrm{R}$ & & & & & & & & & \\
\hline
\end{tabular}

Table VIII : None sine wave $\left(^{*}\right)$ sweep until reaction for FAZ-1N-B6

\begin{tabular}{|l|l|l|l|l|l|l|l|l|l|l|l|l|}
\hline $\begin{array}{c}\text { Test } \\
\text { Voltage }\end{array}$ & \multicolumn{10}{|c|}{ NON-SINE wave current: RMS-values until reaction [A] } \\
\hline \hline $60 \mathrm{~V}$ & & & & 11,1 & & 12,0 & 12,4 & 13,0 & 13,9 & 14,3 & 16,5 & $\mathrm{R}$ \\
\hline $70 \mathrm{~V}$ & 10,8 & 11,3 & 11,9 & 12,7 & 13,1 & 14,1 & 14,8 & 15,3 & 16,4 & 17,0 & $\mathrm{R}$ & \\
\hline $80 \mathrm{~V}$ & 12,5 & 13,2 & 13,9 & 14,8 & 15,1 & 16,3 & 17,1 & $\mathrm{R}$ & & & & \\
\hline $90 \mathrm{~V}$ & 14,0 & 14,8 & 15,5 & 17,1 & $\mathrm{R}$ & & & & & & & \\
\hline $100 \mathrm{~V}$ & 15,7 & 16,6 & $\mathrm{R}$ & & & & & & & & & \\
\hline
\end{tabular}

(*) The analysed signal was in correspondence with the signal given in figure 6

Last given numeral value is the value of reaction of the fuse.

$\mathrm{R}$ means reaction of the fuse, before value can be measured. 
Depending on the current peak, fuse reaction occurs immediately or at the latest half a period later (Fig. 8). However if current peak is increased, fuse reaction will always occur immediately. Tables VII and VIII reveal no relationship for current RMS value in magnetic fuse reaction between sine wave current and non sine wave current. Depending on both, type and mark, fuse reaction will differ quite well. Table IX shows the current peak, RMS and average values at magnetic reaction for different marks and types. Two tested automatic fuses (C4-mark2 and B6-mark3) do not fulfil the normative reference.

Table IX : Non linear current, magnetic behaviour for different types and marks of automatic fuses

\begin{tabular}{|l|c|c|c|}
\hline Fuse & $\mathrm{I}_{\text {piek }}[\mathrm{A}]$ & $\mathrm{I}_{\mathrm{rms}}[\mathrm{A}]$ & $\mathrm{I}_{\mathrm{av}}[\mathrm{A}]$ \\
\hline \hline C2 (mark 1) & 37.1 & 12.4 & 6.6 \\
\hline C4 (mark 2) & 58.2 & 19.4 & 10.3 \\
\hline C4 (mark 3) & 69.1 & 23.0 & 12.3 \\
\hline B6 (mark 3) & 49.0 & 16.3 & 8.7 \\
\hline B10 (mark 3) & 90.6 & 30.2 & 16.1 \\
\hline
\end{tabular}

\subsection{Results of inrush current analysis}

Inrush current analysis for current fingerprint as given in fig. 7 leads to the same results as mentioned in table VI. Different tests are performed and fuse reaction always appears on same peak current.

\section{CONCLUSIONS}

For a test current of $1,13 I_{n}$ sine wave as well as non linear current, automatic fuses meet the normative references. The same conclusions can be drawn considering a test current of 1,45 $I_{n}$ and 2,55 $I_{n}$. Regarding the thermal, steady state conditions, automatic fuses fulfil all requirements of the normative reference.

Concerning the transient, magnetic reaction, all types of automatic fuses fulfil the normative requirements for sine wave conditions. For non linear load conditions, the reaction of the fuses reaches hardly the lower limit of non reaction, however the peak current is $60 \%$ higher than in sine wave conditions. Tests with other fuse values and fuses from other manufacturers give the same conclusions and similar ratings are found for magnetic reaction of the fuses.

Final conclusion: the magnetic reaction of an automatic fuse occurs for non linear RMS currents of IT equipment that are hardly $60 \%$ of the sine wave RMS currents, however the peak values are $60 \%$ higher. Higher classes of fuses are recommended.

\section{ACKNOWLEDGEMENT}

The authors wish to thank the Flemish Government for granting the project "Studie van de nadelige gevolgen van het grootschalig gebruik van verlichting en officeequipment in nutsgebouwen" (IWT-HOBU).

\section{REFERENCES}

[1] J. Desmet, I. Sweertvaegher, G. Vanalme and R. Belmans, "Analysis of electrical and power quality parameters of IT-equipment", Proc. ERA Conf. on Quality and security of electrical supply, Oxford, UK, 26-27 February 2001

[2] J. Desmet, B. Van Heghe, K. Stockman, R.Belmans "A practical approach to the non-linear parameter estimation of a six-pulse full bridge converter with voltage source inverter" Vol. 1 EMC Conf. Brugges, Belgium, 11-15 sept. 2000

[3] A. Mansoor, W.M. Grady, A.H. Chowdhury, J.M. Samotyj, "An investingation of harmonics attenuation and diversity among distributed single phase power electronic loads", IEEE Transactions on power delivery, Vol 10, No 1, January 1995, pp 467-473

[4] T.M. Gruzs, "A survey of neutral currents in threephase computer power systems," IEEE Transactions on Industry Applications, Vol. 26, No. 4, July/August 1990, pp. 719-725

[5] A.-C. Liew, "Excessive neutral currents in threephase fluorescent lighting circuits," IEEE Transactions on Industry Applications, Vol. 25, No. 4, July/August 1989, pp. 776-782

[6] J. Desmet, I. Sweertvaegher, G. Vanalme, K. Stockman and R. Belmans, "Analysis of the neutral conductor current in a three phase supplied network with non-linear single phase load"s, IEMDC/IEEE Conf., MIT, Cambridge, Massachusetts, USA, 17-21 June 2001, electronic proc.

[7] IEC60898, "Circuit breakers for overcurrent protection for household and similar installations" (1995-02)

[8] L. Van der Veken, "Safety and inspection perspective," European Copper Institute: Workshop on economic cost of poor power quality, Brussels, Belgium, 8 June 2000 